\title{
Two Autopsy Cases of Water Intoxication
}

Wataru Kawashima*, Katsuhiko Hatake, Risa Kudo, Mari Nakanishi, Shigehiro Tamaki, Shogo Kasuda, Katsuya Yuui and Akiko Ishitani Department of Legal Medicine, Nara Medical University, 840 Shijo-cho, Kashihara, Nara 634-8521, Japan

\begin{abstract}
We here report two autopsy cases of men with an intellectual disability who died from water intoxication.

(Case 1) A 22-year-old man was found dead in a prone position in his room. Autopsy and histological findings revealed the edema of brain and lung. The serum $\mathrm{Na}$ value was $108 \mathrm{mEq} / \mathrm{L}$.

(Case 2) A 23-year-old man suddenly fell and was found unconscious. Autopsy and histological findings revealed the edema of brain and lung. In lung tissue, deposition of fibrin around the vessels, was found. The serum Na value was $<100 \mathrm{mEq} / \mathrm{L}$.

On the basis of these findings, we concluded that they were died from water intoxication and hyponatremia as a result of massive drinking.

We also discuss new autopsy findings that support the diagnosis of water intoxication and we investigate the serum $\mathrm{Na}$ value of autopsy cases $(\mathrm{N}=17)$ in order to analyses the postmortem change of serum $\mathrm{Na}$ value.
\end{abstract}

Keywords: Forensic science; Water intoxication; Intellectual disability; Hyponatremia; Autopsy; Deposition of fibrin

\section{Introduction}

Water intoxication is a serious condition that results from drinking massive volumes and is characterized by hyponatremia, ataxia, and spasm, often resulting in coma. There are a number of reports of water intoxication in psychiatric patients, such as those with schizophrenia, intellectual disability, or pervasive developmental disorder) [116]. Previous reports indicate that this condition is related to the syndrome of inappropriate antidiuretic hormone secretion [8-12], and delayed treatment can result in serious consequences [17]. Other reports are related to forced drinking as a result of abuse [13,18-21], iatrogenic reasons, or excessive irrigation during endoscopic surgery in gynecological or gastrointestinal settings [17,22].

We report 2 autopsy cases that were considered to be water intoxication and discuss new autopsy findings in support of diagnosis. We also analyzed serum $\mathrm{Na}$ value in order to observation the change of postmortem serum Na value.

\section{Case Reports}

\section{Case 1}

A 22-year-old man was admitted to an institution owing to intellectual disability. He was found dead in a prone position in his room. Approximately 10 days before his death, he had repeatedly drunk considerable volumes, followed by vomiting.

Autopsy findings: The patient's height and weight were $180 \mathrm{~cm}$ and $82.4 \mathrm{~kg}$, respectively. The external examination revealed congestion of the facial region and red-colored fluid in the nasal and oral cavities.

The brain weighed $1540 \mathrm{~g}$, with congestion. The heart weighed 415 $\mathrm{g}$, and sclerosis and stenosis of the coronary arteries were not detected. The lungs weighed $670 \mathrm{~g}$ (left) and $750 \mathrm{~g}$ (right) with a high degree of swelling and presence of red-colored fluid in the trachea and bronchi. The bladder was extremely expanded and contained $910 \mathrm{cc}$ of urine.

Histological analyses revealed prominent congestion and edema of the lung tissue (Figure 1). Other organs did not show any significant findings. Serum Na value was $108 \mathrm{mEq} / \mathrm{L}$.

\section{Case 2}

A 23-year-old man with an intellectual disability entered an institution because of polydipsia. He had habitually and repeatedly drunk considerable volumes and experienced diarrhea and vomiting. This behavior was uncontrollable; therefore, his family decided to admit him. The night of the day following his admission, he suddenly fell and was found unconscious. The patient died despite immediate transport to the emergency room by ambulance.

\section{Autopsy findings}

The patient's height and weight were $166 \mathrm{~cm}$ and $49.4 \mathrm{~kg}$, respectively. The external examination revealed no significant findings except a contusion on the facial region that resulted from his fall.

The brain weighed $1383 \mathrm{~g}$, with congestion. The heart weighed 328 $\mathrm{g}$, and sclerosis and stenosis of the coronary arteries were not detected. The lungs weighed $422 \mathrm{~g}$ (left) and $509 \mathrm{~g}$ (right) with a high degree of swelling; the trachea and bronchi were empty. The greater curvature of the stomach was ruptured because of cardiac massage, and $3100 \mathrm{cc}$ of fluid with food debris was observed in the intraperitoneal space (Figure 2). The bladder was empty, likely because of urethral catheterization.

Histological analyses revealed edema of the subarachnoid space. Protrusion and surrounding vacuolization were observed at the cardiac vessels (Figure 3a). A portion of the cardiac muscle bundles was expanded (Figure $3 b$ ). The lungs showed fluid in the bronchi (Figure

*Corresponding author: Wataru Kawashima, Department of Legal Medicine Nara Medical University School of Medicine, 840 Shijo-cho, Kashihara, Nara 634-8521, Japan, Tel: +81-744-29-8843; Fax: +81-744-29-1116; E-mail: watack14@naramed-u.ac.jp

Received January 07, 2015; Accepted February 13, 2015; Published February 20, 2015

Citation: Kawashima W, Hatake K, Kudo R, Nakanishi M, Tamaki S, et al (2015) Two Autopsy Cases of Water Intoxication. J Forensic Res 6: 271. doi: 10.4172/2157-7145.1000271

Copyright: @ 2015 Kawashima W, et al. This is an open-access article distributed under the terms of the Creative Commons Attribution License, which permits unrestricted use, distribution, and reproduction in any medium, provided the original author and source are credited. 


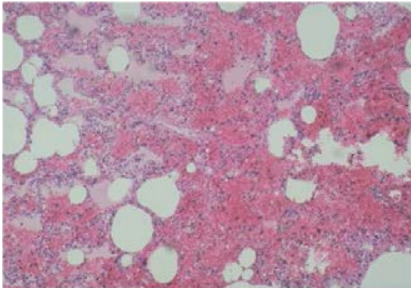

a

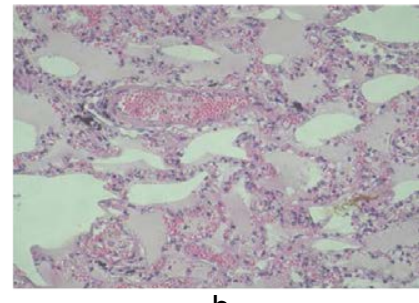

b
Figure 1: Congestion and edema of the lung tissue. (a) $\times 100$ Hematoxylin-Eosin staining, (b) $\times 200$ Hematoxylin-Eosin staining.

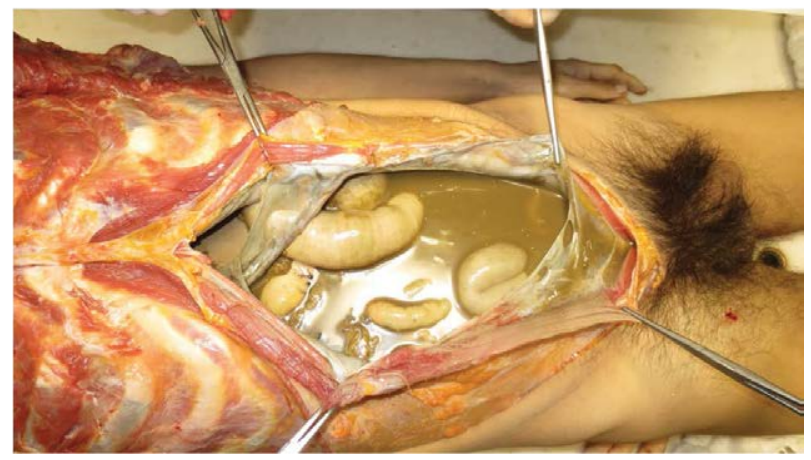

Figure 2: Fluid with food debris was observed in the intraperitoneal space.

4a), expansion of the capillary vessels, and deposition of fibrin around the vessels (Figure $4 \mathrm{~b}$ and $4 \mathrm{c}$ ). The kidney showed edema of the tubular epithelium. Serum Na value was $<100 \mathrm{mEq} / \mathrm{L}$.

\section{Evaluation of Serum Na Values}

To investigate changes in the postmortem Na value, we investigated the serum $\mathrm{Na}$ value in 17 autopsy cases from our institution and evaluated the relationship between the $\mathrm{Na}$ value and time after death (12-168 h). In this analysis, the serum $\mathrm{Na}$ value was between 109 and $138 \mathrm{mEq} / \mathrm{L}$, and the $\mathrm{Na}$ value was low in almost all of the cases, compared with the normal Na range (135-145 mEq/ L). No relationship between the $\mathrm{Na}$ value and time after death (12-168 h) was detected. Two cases with a $\mathrm{Na}$ value $<110(\mathrm{Na}=109$ and 110$)$ had both received a massive transfusion before death.

\section{Discussion}

In previous reports of water intoxication, the diagnostic criteria included excessive drinking, presence of large volumes of fluid in the stomach, macroscopic and histological evidence of edema of the brain and lung tissue, a low serum $\mathrm{Na}$ value, and the absence of endogenous diseases as the cause of death [13].

The serious consequences of water intoxication can result from hyponatremia progression, which involves loss of consciousness, coma, and death, or from asphyxia as a result of aspiration of vomited water during decreased consciousness. In addition, brain herniation has been previously determined to cause fatalities from water intoxication; water intoxication causes changes in serum osmotic pressure leading to brain edema, and brain edema often results in brain herniation. The serum $\mathrm{Na}$ value in these previous cases was approximately lower than $120 \mathrm{mEq} / \mathrm{L}$; therefore, brain herniation, rather than hyponatremia, was considered the cause of death.
Brain herniation was not observed in the present cases; we considered water intoxication as the cause of death owing to the excessive drinking, and judging from the macroscopic and histological evidence of edema of the brain and lung tissue, low serum $\mathrm{Na}$ value, and absence of endogenous diseases that could result in death.

The cause of hyponatremia was considered the long-term antipsychotic drug use; these drugs tend to stimulate the hypothalamus. Furthermore, the majority of water intoxication cases are psychiatric patients, such as those with schizophrenia. The stimulation of the hypothalamus can result in polydipsia and increase extracellular fluid because of the change in serum osmotic pressure. Moreover, antidiuretic hormone secretion was increased, and the serum $\mathrm{Na}$ value was low, resulting in severe hyponatremia.

However, patients who are not administered antipsychotic drugs can also experience water intoxication, indicating that other causes exist. First, polydipsia occurs, drinking increases, and self-induced water intoxication occurs, resulting in hyponatremia. Therefore, hyponatremia can result in the serious consequences of water intoxication and provides proof that hyponatremia is an important diagnostic criterion for water intoxication.

However, at autopsy, the use of the serum $\mathrm{Na}$ value for water intoxication diagnosis may not be reliable because of postmortem changes [23]. In the present analysis, no relationship between the $\mathrm{Na}$ value and time after death was detected. Furthermore, 2 cases with a $\mathrm{Na}$ value $<110 \mathrm{mEq} / \mathrm{L}(\mathrm{Na}=109$ and $110 \mathrm{mEq} / \mathrm{L})$ had both received a massive transfusion before death. Therefore, we consider that the postmortem change in the serum Na value was affected by antemortem circulating body fluid volume.

Case 1 did not receive a transfusion; therefore, the serum $\mathrm{Na}$ value was remarkably low before death, and he was diagnosed with hyponatremia. The serum $\mathrm{Na}$ value in Case 2 was also very low $(<100$ $\mathrm{mEq} / \mathrm{L}$ ). Although Case 2 received a transfusion, we considered the serum $\mathrm{Na}$ value to be very low before death because we did not detect $\mathrm{Na}$ value $<100 \mathrm{mEq} / \mathrm{L}$ in any cases in our analytical study. Therefore, we suggest that the serum Na value in Case 2 decreased to $<100 \mathrm{mEq} / \mathrm{L}$ not only because of the transfusion but also as a result of drinking a massive amount before death.

In Case 2, fibrin deposition in the lungs, edema in the heart, and edema in the kidney were found; these findings have not been reported previously. The deposition of fibrin was considered to be a result of plasma component discharge from the vessels. This phenomenon seems to occur because of changes in serum osmotic pressure and endothelial cell disorders owing to chronic, repeated drinking of massive volumes.

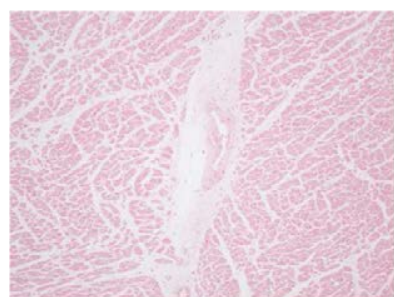

a

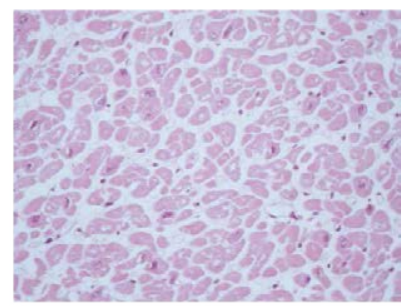

b
Figure 3: Histological findings of heart tissue. (a) Surrounding vacuolization of the cardiac vessels ( $\times 100$ Hematoxylin-Eosin staining) (b) A portion of the cardiac muscle bundles was expanded ( $\times 400$ Hematoxylin-Eosin staining). 


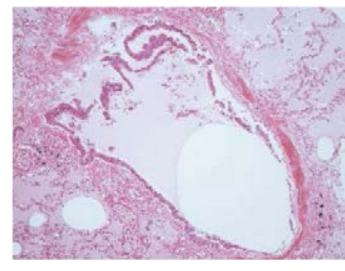

a

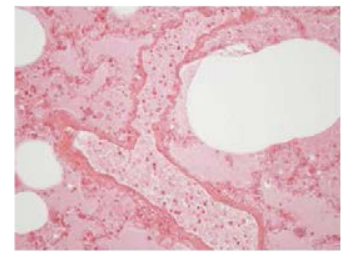

b

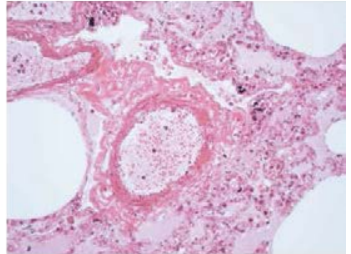

C
Figure 4: Histological findings of lung tissue (a) Fluid in the bronchi ( $\times 100$ Hematoxylin-Eosin staining) (b) (c) Deposition of fibrin around the vessels $(\times 200$ Hematoxylin-Eosin staining).

We believe the autopsy findings of the present cases and analyses of the postmortem serum $\mathrm{Na}$ value are helpful to diagnose water intoxication, and water intoxication should be considered during autopsy in cases of schizophrenia or intellectual disability.

\section{References}

1. Farrell DJ, Bower L (2003) Fatal water intoxication. J Clin Pathol 56: 803-804.

2. Vucicevic Z Degoricija V, Alfirevic Z, Vukicevic-Badouin D (2007) Fatal hyponatremia and other metabolic disturbances associated with psychotropic drug polypharmacy. Int J Clin Pharmacol Ther 45: 289-292.

3. Poirier S, Legris G, Tremblay P, Michea R, Viau-Guay L, et al. (2010) Schizophrenia patients with polydipsia and water intoxication are characterized by greater severity of psychotic illness and a more frequent history of alcohol abuse. Schizophr Res 118: 285-291.

4. Gardner JW (2002) Death by water intoxication. Mil Med 167: 432-434.

5. DiMaio VJ, DiMaio SJ (1980) Fatal water intoxication in a case of psychogenic polydipsia. J Forensic Sci 25: 332-335.

6. Peh LH Devan GS, Low BL (1990) A fatal case of water intoxication in a schizophrenic patient. Br J Psychiatry 156: 891-894.
7. Kushnir M Schattner A, Ezri T, Konichezky S (1990) Schizophrenia and fatal self-induced water intoxication with appropriately-diluted urine. Am J Med Sci 300: 385-387.

8. de Leon J Dadvand M, Canuso C, Odom-White A, Stanilla J, et al. (1996) Polydipsia and water intoxication in a long-term psychiatric hospital. Biol Psychiatry 40: 28-34

9. Shutty MS Jr (1996) Cigarette use, drinking and voiding in schizophrenic patients with polydipsia and hyponatremia. Schizophr Res 21: 195-197.

10. Ellinas PA Rosner F, Jaume JC (1993) Symptomatic hyponatremia associated with psychosis, medications, and smoking. J Natl Med Assoc 85: 135-141.

11. Siegler EL, Tamres D, Berlin JA, Allen-Taylor L, Strom BL (1995) Risk factors for the development of hyponatremia in psychiatric inpatients. Arch Intern Med 155: 953-957.

12. Verghese C De Leon J, Simpson GM (1993) Neuroendocrine factors influencing polydipsia in psychiatric patients: an hypothesis. Neuropsychopharmacology 9: 157-166.

13. Radojevic N Bjelogrlic B, Aleksic V, Rancic N, Samardzic M, et al. (2012) Forensic aspects of water intoxication: four case reports and review of relevant literature. Forensic Sci Int 220: 1-5

14. Loas G Mercier-Guidez E (2002) Fatal self-induced water intoxication among schizophrenic inpatients. Eur Psychiatry 17: 307-310.

15. Hayashi T Ishida Y, Miyashita T, Kiyokawa H, Kimura A, et al. (2005) Fatal water intoxication in a schizophrenic patient--an autopsy case. J Clin Forensic Med 12: 157-159.

16. Vieweg WV, David JJ, Rowe WT, Wampler GJ, Burns WJ, et al. (1985) Death from self-induced water intoxication among patients with schizophrenic disorders. J Nerv Ment Dis 173: 161-165.

17. Chen X Huang G (1995) Autopsy case report of a rare acute iatrogenic water intoxication with a review of the literature. Forensic Sci Int 76: 27-34.

18. Arieff Al Kronlund BA (1999) Fatal child abuse by forced water intoxication. Pediatrics 103: 1292-1295.

19. Barber GA Whitefield JS (2012) Cultivated child abuse: a 2-year-old with hyponatremic seizures. Pediatr Emerg Care 28: 1234-1235.

20. Lin CY Tsau YK (2005) Child abuse: acute water intoxication in a hyperactive child. Acta Paediatr Taiwan 46: 39-41.

21. Tilelli JA, Ophoven JP (1986) Hyponatremic seizures as a presenting symptom of child abuse. Forensic Sci Int 30: 213-217.

22. Camkurt MA CoÄŸkun F, Aksu NM, Akpinar E, Ay D (2010) latrogenic water intoxication after pelvic ultrasonography imaging. Am J Emerg Med 28: 385.

23. Palmiere C Mangin P (2012) Postmortem chemistry update part II. Int J Legal Med 126: 199-215. 